\title{
MGMT methylation alterations in brain cancer following organochlorine pesticides exposure
}

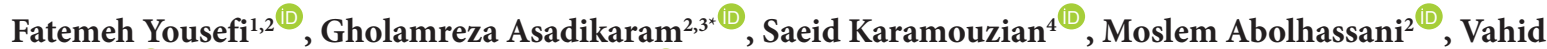 \\ Moazed $^{5^{\circledR}}$, Mohammad Hadi Nematollahi' ${ }^{2,6^{\circledR}}$ \\ ${ }^{1}$ Neuroscience Research Center, Institute of Neuropharmacology, Kerman University of Medical Sciences, Kerman, Iran \\ ${ }^{2}$ Department of Clinical Biochemistry, Faculty of Medicine, Kerman University of Medical Sciences, Kerman, Iran \\ ${ }^{3}$ Endocrinology Research Center, Institute of Basic and Clinical Physiology Sciences, Kerman University of Medical Sciences, Kerman, \\ Iran \\ ${ }^{4}$ Department of Neurosurgery, Faculty of Medicine, Kerman University of Medical Sciences, Kerman, Iran \\ ${ }^{5}$ Department of Hematology and Oncology, Faculty of Medicine, Kerman University of Medical Sciences, Kerman, Iran \\ ${ }^{6} \mathrm{Herbal}$ and Traditional Medicines Research Center, Kerman University of Medical Sciences, Kerman, Iran
}

\begin{abstract}
Background: Alterations in the methylation levels of tumor suppressor genes are considered as one of the essential aspects of malignancies. The present study explored the association of O6-methylguanineDNA methyltransferase (MGMT) gene promoter methylation, as a tumor suppressor, with some organochlorine pesticides (OCPs) in primary brain tumor (PBT) patients.

Methods: The present study was conducted on a total of 73 PBT patients. The patients' serum was analyzed using gas chromatography for seven OCP derivatives. The methylation-specific PCR (MSP) method was also used to determine the methylation status of the MGMT promoter.

Results: The current findings demonstrated that the methylation of MGMT promoter occurred in 22 out of 34 glioma cases (64\%), but in only one out of 35 meningioma cases. No MGMT promoter methylation was observed in other PBT, hemangioma, and anaplastic medulloblastoma stages. Besides, there were significant associations between MGMT methylation and $\gamma-\mathrm{HCH}$ (odds ratio [OR]: 1.50; 95\% CI: 1.03- 2.40, $P=0.04$ ), 4,4DDE (OR: 1.44; 95\% CI: 1.01- 2.05, $P=0.02$ ), 2,4 DDT (OR: 1.23; CI: 1.04- $1.45, P=0.03$ ), and 4,4DDT (OR: 1.46; CI: $1.23-2.15, P=0.02$ ) in glioma patients.

Conclusion: The results of the study suggested that the hypermethylation of the MGMT promoter in glioma patients is associated with increased OCPs in their serum, especially $\gamma$ - HCH, 4,4DDE, 2,4DDT, and 4,4DDT. Moreover, it may lead to the hypermethylation of the MGMT promoter gene. Hence, it can be concluded that exposure to OCPs may potentially induce glioma.

Keywords: Organochlorine, Pesticides, MGMT, DNA Methylation, Glioma

Citation: Yousefi F, Asadikaram G, Karamouzian S, Abolhassani M, Vahid Moazed, Mohammad Hadi Nematollahi. MGMT methylation alterations in brain cancer following organochlorine pesticides exposure. Environmental Health Engineering and Management Journal 2021; 8(1): 47-53. doi: 10.34172/EHEM.2021.07.
\end{abstract}

\author{
Article History: \\ Received: 4 December 2020 \\ Accepted: 18 January 2021 \\ ePublished: 27 February 2021
}

\section{Introduction}

Despite an enormous amount of research and rapid developments during the past decade, there is no definitive cure for cancer even though it is believed to be preventable. Only $5 \%-10 \%$ of all cancer cases can be attributed to genetic defects, whereas the remaining $90 \%-95 \%$ are associated with environmental pollutants and lifestyle (1). Because of their slow degradation and high persistence in the environment, organochlorine pesticides (OCPs) are considered as one of the most critical types of environmental pollutants with a high human exposure rate (2). Moreover, given the bioaccumulation of OCPs in fatty tissues, these pesticides have been observed in various human tissues in enormous amounts (2). Previous studies have shown that long-term exposure to these pesticides increases the risk of developing multiple types of cancer (3-5). One of the critical mechanisms considered to be associated with the role of pesticides in the development of cancers is epigenetic modifications (6). As a well-known epigenetic modification, DNA methylation occurs in CpG islands without making any DNA sequence alterations (7). In an in vitro study, Zhang et al showed that pesticide exposure could alter DNA methylation levels (8). This paper was focused on O6-methylguanine-DNA methyltransferase (MGMT) methylation in primary brain tumor (PBT) patients. PBT is divided into two main categories: glioma 
and meningioma. Glioma accounts for more than $70 \%$ of all brain tumors including pilocytic astrocytoma (grade I), astrocytoma (grade II), anaplastic astrocytoma (grade III), and Glioblastoma multiforme (grade IV). Meningioma accounts for the remaining 30\% of brain tumors, such as meningioma (grade I), schwannoma (grade II), and lymphoma (grade III) (9). The MGMT gene encodes an enzyme that repairs the damage caused by DNA alkylating agents (10). Previous studies have shown that the lack of MGMT gene function in cancer cells is caused by the gene promoter hypermethylation, which leads to MGMT gene silencing $(11,12)$. Another study provided direct experimental evidence showing that pesticides are associated with changes in promoter methylation in numerous genes such as MGMT that is reported to be involved in the increased risk of cancer development in humans (8). Kreth et al, in their review study, pointed out that hypermethylation mostly occurs at the CpG islands of the MGMT promoter in glioma. Moreover, the methylation patterns differ among different glioma grades (13). The present study sought to investigate whether OCPs derivatives are associated with the MGMT promoter methylation regarded as an important tumor suppressor in PBT. For this purpose, glioma patients' serum was analyzed using gas chromatography for seven derivatives of OCPs, i.e. $\alpha-\mathrm{HCH}, \beta-\mathrm{HCH} \gamma-\mathrm{HCH}, 4,4 \mathrm{DDE}, 2,4 \mathrm{DDT}$, and 4,4DDT. Furthermore, methylation status of MGMT promoter was assessed using the methylation-specific PCR (MSP) method.

\section{Materials and Methods \\ Subjects}

The present study was conducted on 73 patients admitted to Shahid Bahonar hospital of Kerman University of Medical Sciences, Kerman, Iran from February 2017 to July 2019. The patients were diagnosed with a brain tumor and underwent surgery. They were selected based on clinical examination and pathological findings by an expert neurosurgeon. The patients' PBT stage was determined based on the tumor node metastasis staging system. All patients who had any history of surgery, radiotherapy, and chemotherapy, or metastasized cancer from other tissues to the brain were excluded from the study. Following the surgery, tissue specimens were obtained from the patients and immediately frozen at $-80^{\circ} \mathrm{C}$ until further analysis. The PBT patients' mean age and BMI were 49.5 years and 26.54 , respectively. Besides, over half of the patients (55\%) were engaged in farming activities (Table 1). Of 73 PBT patients, $45 \%$ and 55\% were men and women, respectively (Table 1), and most of them had a meningioma (48\%) (Table 2).

\section{Sample and data collection}

Blood samples were collected from the studied patients before surgery and were then centrifuged to separate serum elements. Then, the samples were divided into single-use aliquots and kept frozen at $-80{ }^{\circ} \mathrm{C}$ for further assessment. The PBT patients' serum was used for the measurement of OCPs via gas chromatography. The tumor tissue samples were acquired from the PBT patients following surgery and then frozen at $-80^{\circ} \mathrm{C}$ until further analysis. The tissue specimens were used to assess MGMT methylation through the MSP method.

\section{Methylation-specific PCR}

Using Favorgen Kit (Cat No. FATGK001), the patients' DNAs were extracted and kept at -80 until further assessment.

The basis of the MSP method is DNA reaction with sodium bisulfite, which leads to the conversion of cytosine to uracil and subsequently to thymidine in PCR steps. Still, methylated cytosine remains unchanged (14). According to a method proposed by Tiwari et al (15), extracted DNA

Table 1. Demographic and clinical characteristics of the subjects

\begin{tabular}{|c|c|c|c|}
\hline Variables & $\begin{array}{l}\text { Glioma } \\
(n=34)\end{array}$ & $\begin{array}{l}\text { Meningioma } \\
\quad(n=35)\end{array}$ & $P$ value \\
\hline Gender, No. (\%) & & & $0.15^{b}$ \\
\hline Male & $18(52)$ & $13(37)$ & \\
\hline Female & $16(47)$ & $22(63)$ & \\
\hline $\begin{array}{l}\text { Age (year) } \\
\text { Min-Max }\end{array}$ & $47.34 \pm 2.35$ & $49.00 \pm 2.63$ & $0.63^{\mathrm{a}}$ \\
\hline BMI $\left(\mathrm{kg} / \mathrm{m}^{2}\right)$ & $25.28 \pm 0.56$ & $26.14 \pm 0.62$ & $0.30^{\mathrm{a}}$ \\
\hline Education level, No. (\%) & & & $0.95^{b}$ \\
\hline High school or less & $20(59)$ & $22(63)$ & \\
\hline Greater than high school & $14(41)$ & $13(37)$ & \\
\hline Residence, No. (\%) & & & $0.01^{\mathrm{b}}$ \\
\hline North of Kerman & $20(59)$ & $10(28)$ & \\
\hline South of Kerman & $14(41)$ & $25(72)$ & \\
\hline Farming activities, No. (\%) & & & $0.49^{b}$ \\
\hline No & $14(41)$ & $17(48)$ & \\
\hline Yes & $20(59)$ & $18(52)$ & \\
\hline Smoking, No. (\%) & & & $0.23^{b}$ \\
\hline No & $13(38)$ & $20(57)$ & \\
\hline Yes & $21(62)$ & $15(43)$ & \\
\hline $\begin{array}{l}\text { Family history of cancer, } \\
\text { No. }(\%)\end{array}$ & & & $0.64^{b}$ \\
\hline No & $19(56)$ & $17(48)$ & \\
\hline Yes & $15(44)$ & $18(52)$ & \\
\hline TG (mg/dL) & $108.95 \pm 11.46$ & $140.11 \pm 11.69$ & $0.06^{c}$ \\
\hline Cholesterol (mg/dL) & $154.68 \pm 9.18$ & $161.74 \pm 9.13$ & $0.58^{c}$ \\
\hline $\mathrm{HDL}(\mathrm{mg} / \mathrm{dL})$ & $38.70 \pm 1.70$ & $39.11 \pm 2.33$ & $0.88^{\circ}$ \\
\hline LDL (mg/dL) & $95.18 \pm 7.37$ & $94.60 \pm 7.26$ & $0.96^{c}$ \\
\hline
\end{tabular}

Abbreviations: BMI, Body mass index; TG, triglycerides; HDL, high-density lipoprotein; LDL, low-density lipoprotein.

$P$ value demonstrates the differences between the glioma and the meningioma patients. A significant difference $(P<0.05)$. Continuous and categorical values are expressed as mean \pm SD.

${ }^{\mathrm{a}}$ Independent sample $t$ test; ${ }^{\mathrm{b}} \mathrm{Chi}$-square/Fisher exact test; ' $\mathrm{c}$ Mann-Whitney $U$ test. 
was treated with sodium bisulfite. The modified DNA sequence was amplified by PCR with specific primers of methylated and unmethylated DNA (Table 3). Methylated primers detect unchanged cytosines, and unmethylated primers identify thymines derived from modified cytosines in the MGMT promoter region. After PCR, the products were loaded on $2 \%$ agarose gel, and electrophoresis was performed. Then, the results were interpreted based on the presence or absence of the relevant band in the agarose gel (Figure 1B).

\section{Measuring the organochlorine pesticides in the patients' serum}

The standards of seven OCPs derivatives were purchased from Pestana (Germany), and 4,4-dichlorobenzophenone (the internal standard) was acquired from Sigma-Aldrich (USA).

OCPs residues were extracted using hexane and sulfuric acid according to the method offered by Zumbado et al (16). In summary, the internal standard was added to 0.5 $\mathrm{mL}$ of serum. The specimens were extracted two times, with $2 \mathrm{~mL}$ of hexane. Then, $200 \mu \mathrm{L}$ of concentrated sulfuric acid was added to the combined extract, leading to the separation of its organic part, which was dehydrated using $200 \mathrm{mg}$ of anhydrous sodium sulfate. Upon centrifuging, the organic layer was entirely concentrated at room temperature. After evaporation of the solvent, the addition of $100 \mu \mathrm{L}$ of ethyl acetate made the samples ready for injection into the gas chromatography (GC-FID, Agilent 7890A, USA).

\section{Statistical analysis}

All continuous variables were presented as mean \pm standard deviation and categorical variables as numbers (percentages). The Kolmogorov-Smirnov test was used to check the normality of the variables. The quantitative and qualitative variables between glioma and meningioma patients were compared using the independent samples t-test, Mann-Whitney $U$ test, chi-square, and Fisher's exact test. The associations between OCPs and methylation status of MGMT in the glioma patients were estimated using the continuous logistic regression model adjusted for age, BMI, total lipids, farming activities, and place of residence. To examine whether the methylation status of MGMT could modify the effects of OCPs exposure in glioma, the patients were divided into low or high exposure categories based on the median serum concentrations of OCPs. Afterward, the logistic regression was applied to investigate possible interactions between MGMT methylation and OCPs exposure. All analyses were performed by SPSS 21.0 for Windows (IBM/SPSS Inc., New York, USA). $P$ values less than 0.05 were considered significant.

\section{Results}

The current findings showed the methylation of the MGMT gene in 22 out of 34 glioma cases (64\%), along with the methylation of the MGMT gene in only one out of 35 meningioma cases. However, no methylation was observed in the MGMT promoter in other PBT, hemangioma, and anaplastic medulloblastoma stages (Figure 1A).

The results of this study also revealed that $76 \%$ of the PBT patients, hypermethylated in MGMT promoter, had body mass index (BMI) above 25 , and that $52 \%$ of patients who were unmethylated in MGMT promoter had $\mathrm{BMI}<25$ (Figure 2). Moreover, the results showed that $76 \%$ of the patients who were hypermethylated in MGMT promoter were farmers and that $56 \%$ of patients who were unmethylated in MGMT promoter had no

Table 2. Distribution of PBT cases and the average tumor volumes according to histological stage

\begin{tabular}{|c|c|c|c|}
\hline $\begin{array}{l}\text { Histological Type } \\
\text { No. (\%) }\end{array}$ & & $\begin{array}{l}\text { Subjects } \\
N=73(\%)\end{array}$ & $\begin{array}{c}\text { Tumor volume } \\
\text { Mean } \pm \text { SD }\end{array}$ \\
\hline \multirow{4}{*}{$\begin{array}{l}\text { Gliomas } \\
34(46.6)\end{array}$} & Pilocytic Astrocytoma (grade I) & $5(6.8)$ & $12.41 \pm 12.04$ \\
\hline & Astrocytoma (grade II) & $6(8.2)$ & $3.37 \pm 3.71$ \\
\hline & Anaplastic astrocytoma (grade III) & $8(11)$ & $5.56 \pm 8.36$ \\
\hline & Glioblastoma multiforme (grade IV) & $15(20.5)$ & $25.88 \pm 31.85$ \\
\hline \multirow{3}{*}{$\begin{array}{l}\text { Meningioma } \\
35(48)\end{array}$} & Meningioma & $18(24.6)$ & $19.78 \pm 18.62$ \\
\hline & Schwannoma & $10(13.6)$ & $30.60 \pm 38.75$ \\
\hline & Lymphoma & $7(9.6)$ & 14 \\
\hline \multirow{2}{*}{$\begin{array}{l}\text { Other } \\
4(5.5)\end{array}$} & Haemangioma & $3(4.1)$ & $2.87 \pm 3.0$ \\
\hline & Anaplastic medulloblastoma & $1(1.4)$ & $1.75 \pm 0.35$ \\
\hline
\end{tabular}

Table 3. Primer sequences, annealing temperature, and amplicon sizes of MGMT in MSP

\begin{tabular}{lcccc}
\hline Gene name & Primer sequences (5-3) forward & Primer sequences (5-3) reverse & Annealing temperature & Product size (bp) \\
\hline Methylated & TTTCGACGTTCGTAGGTTTTCGC & GCACTCTTCCGAAACGAACG & 68 \\
Unmethylated & TTTGTGTTTTGATGTTTGTAGGTTTTTGT & AACTCCACACTCTTCCAAAAACAAAACA & 64 & 93 \\
\hline
\end{tabular}


A
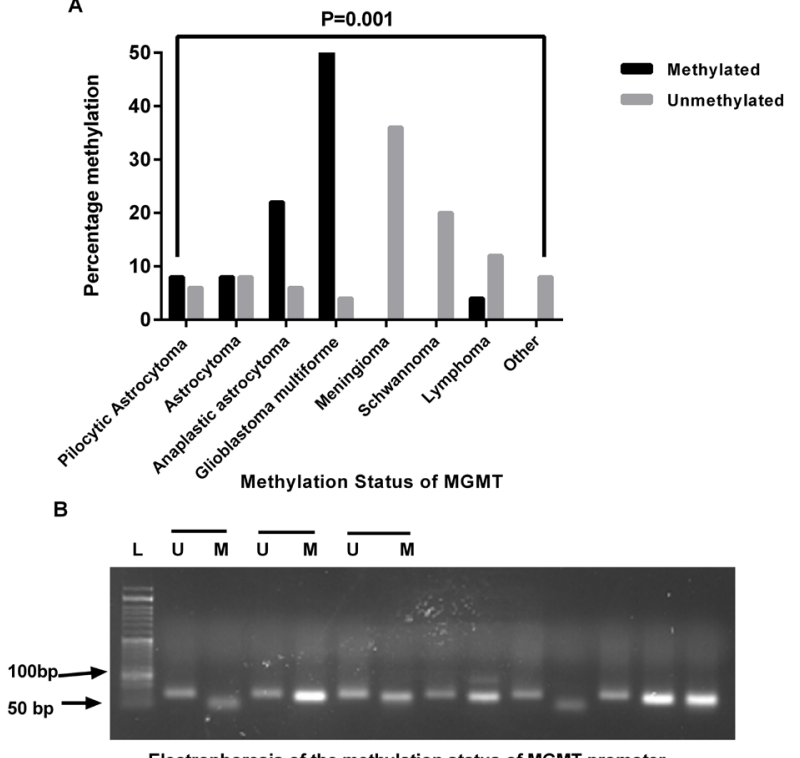

Electrophoresis of the methylation status of MGMT promoter

Figure 1. (A) The bar graph shows the percentage of different statuses of MGMT promoter methylation in PBT patients. Chisquare test was utilized. (B) the electrophoresis picture of the methylation statuses of MGMT promoter regions by MSP. L: DNA ladder; M: methylated band; U: Un-methylated band. The methylated band is $81 \mathrm{bp}$ and the unmethylated band is $93 \mathrm{bp}$.

agricultural activity (Figure 2). No significant relationship was found between MGMT methylation status and tumor size in the PBT patients. The mean pesticides levels in the methylated and unmethylated status of the MGMT gene in the glioma patients are shown in Table 4. The mean levels of $\gamma$ - HCH $(P=0.019), 4,4 \mathrm{DDE}(P=0.037), 2,4 \mathrm{DDT}$ $(P=0.006)$ and $4,4 \mathrm{DDT} \quad(P=0.043)$ were statistically different between the unmethylated and methylated of MGMT gene. After adjusting for confounders, age, BMI, total lipids, farming activities, and place of residence, odds ratio showed that there were significant associations between MGMT methylation and $\gamma-\mathrm{HCH}$ (odds ratio [OR]: 1.50; 95\% CI: 1.03- 2.40, $P=0.04$ ), 4,4DDE (OR: 1.44; 95\% CI: 1.01- 2.05, $P=0.02$ ), 2,4 DDT (OR: 1.23; CI: 1.04- 1.45, $P=0.03$ ), and 4,4DDT (OR: 1.46; CI: 1.23- 2.15, $P=0.02$ ) in the glioma patients (Table 5). Furthermore, in the interaction analysis, after adjusting for confounders (age, BMI, total lipids, farming activities, and place of residence), significant interactions were observed between MGMT methylation and OCPs (Figure 3). The adjusted odds ratio (AOR) for glioma patients with methylated MGMT and exposure to high-level OCPs suggested that glioma risk was elevated 4.80 folds for $\mathrm{\Sigma HCHs}$ (the molar sums of $\alpha-\mathrm{HCH}, \beta-\mathrm{HCH}$, and $\gamma-\mathrm{HCH}$ ), 5.66 folds for $\Sigma$ DDEs (the molar sums of 2,4 DDE and 4,4 DDE), and 6.25 folds for $\Sigma$ DDTs (the molar sums of 2,4 DDT and 4,4 DDT) compared to the reference.

\section{Discussion}

Alterations in the methylation levels of tumor suppressor genes are considered as one of the crucial aspects of malignancies (3). This study investigated the methylation status of MGMT, a tumor suppressor, in 73 PBT patients. MGMT gene expression can be silenced by promoter methylation. Hypermethylation in specific regions of the MGMT promoter was reported in some malignancies including gliomas, colorectal cancer, breast cancer, and melanoma (14). Previous studies have shown that hypermethylation mostly occurs in MGMT promoter CpG islands and that the methylation patterns differ among different glioma grades (13). A study conducted by Zhang et al provided direct experimental evidence that pesticides are associated with changes in promoter CpG methylation in numerous genes such as MGMT that increased cancer risk in humans (8). The findings of the present study demonstrated methylation of the MGMT gene promoter in $64 \%$ of gliomas. Different studies have reported the mean methylation of the MGMT gene in glioma as $40-74 \%$ (17). In the present study, a significantly higher percentage of MGMT methylation was found in high-grade gliomas (glioblastoma multiform, 13 of 15 cases), which may account for the deterioration of patients
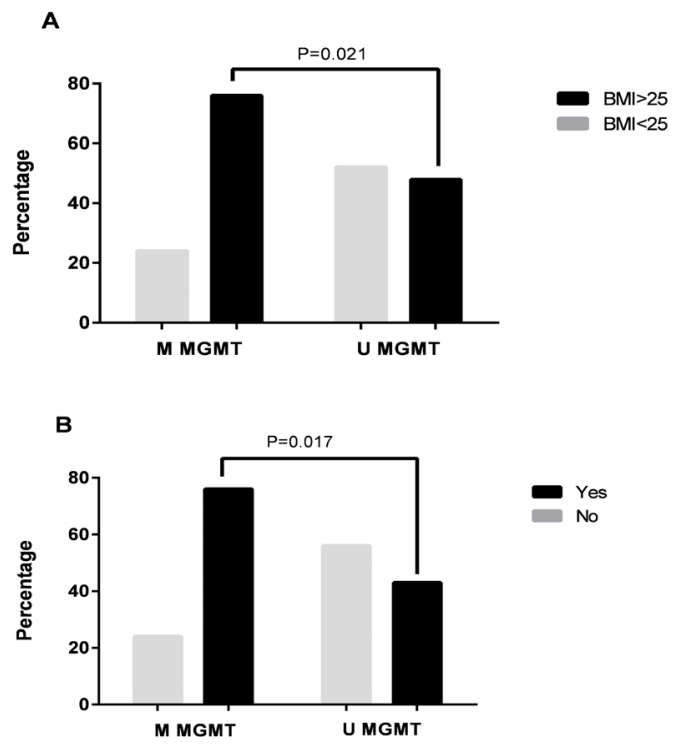

C

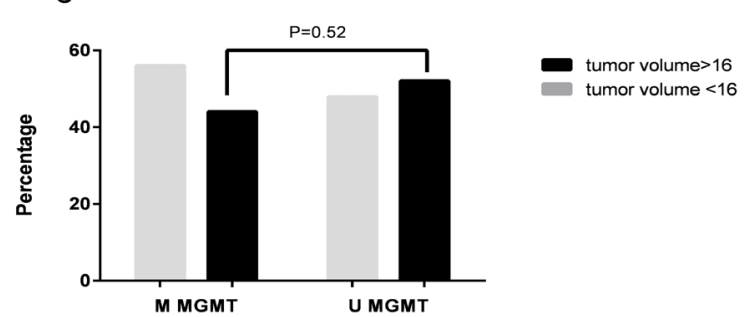

Figure 2. (A) The percentage of different statuses of MGMT promoter methylation in PBT patients based on BMI. (B) The percentage of different statuses of MGMT promoter methylation in PBT patients based on farming activities. (C) The percentage of different statuses of MGMT promoter methylation in PBT patients based on tumor size. 
Table 4. The mean levels of OCPs in methylated and unmethylated status in glioma patients

\begin{tabular}{lccc}
\hline \multicolumn{4}{c}{ Glioma $(\mathbf{n = 3 4 )}$} \\
\hline OCPs & Unmethylated $(\mathbf{n = 1 2})$ & Methylated $(\mathbf{n = 2 2})$ & $\boldsymbol{P}$ value \\
\hline $\mathrm{a}-\mathrm{HCH}$ & $1.67 \pm 0.96$ & $1.54 \pm 0.85$ & 0.57 \\
\hline$\beta-\mathrm{HCH}$ & $0.73 \pm 0.50$ & $0.62 \pm 0.40$ & 0.70 \\
\hline $\mathrm{Y}-\mathrm{HCH}$ & $0.70 \pm 0.43$ & $1.39 \pm 1.01$ & 0.019 \\
\hline $2,4 \mathrm{DDE}$ & $5.47 \pm 2.83$ & $5.40 \pm 2.32$ & 0.92 \\
\hline $4,4 \mathrm{DDE}$ & $1.22 \pm 0.91$ & $1.92 \pm 1.23$ & 0.037 \\
\hline $2,4 \mathrm{DDT}$ & $4.88 \pm 2.23$ & $7.07 \pm 4.33$ & 0.006 \\
\hline $4,4 \mathrm{DDT}$ & $3.07 \pm 1.37$ & $5.70 \pm 1.09$ & 0.043
\end{tabular}

$P$ value demonstrates the difference between unmethylated and methylated states.

Significance difference $(P<0.05)$

Table 5. Association between OCPs and methylation status of MGMT in glioma patients

\begin{tabular}{|c|c|c|c|c|}
\hline OCPs & $\begin{array}{c}\text { Unadjusted OR } \\
(95 \% \mathrm{Cl})\end{array}$ & $P$ value & $\begin{array}{l}\text { Adjusted OR } \\
(95 \% \mathrm{Cl})\end{array}$ & $P$ value \\
\hline $\mathrm{a}-\mathrm{HCH}$ & $\begin{array}{c}0.77 \\
(0.39-1.49)\end{array}$ & 0.57 & $\begin{array}{c}0.85 \\
(0.49-1.47)\end{array}$ & 0.55 \\
\hline$\beta-\mathrm{HCH}$ & $\begin{array}{c}0.67 \\
(0.22-2.05)\end{array}$ & 0.69 & $\begin{array}{c}0.85 \\
(0.38-1.88)\end{array}$ & 0.37 \\
\hline $\mathrm{Y}-\mathrm{HCH}$ & $\begin{array}{c}1.63 \\
(1.02-2.62)\end{array}$ & 0.03 & $\begin{array}{c}1.50 \\
(1.03-2.40)\end{array}$ & 0.04 \\
\hline 2,4 DDE & $\begin{array}{c}0.89 \\
(0.70-1.13)\end{array}$ & 0.91 & $\begin{array}{c}0.99 \\
(0.82-1.19)\end{array}$ & 0.44 \\
\hline 4,4 DDE & $\begin{array}{c}1.58 \\
(1.03-2.40)\end{array}$ & 0.04 & $\begin{array}{c}1.44 \\
(1.01-2.05)\end{array}$ & 0.02 \\
\hline 2,4 DDT & $\begin{array}{c}1.38 \\
(1.11-1.70)\end{array}$ & 0.01 & $\begin{array}{c}1.23 \\
(1.04-1.45)\end{array}$ & 0.03 \\
\hline 4,4 DDT & $\begin{array}{c}1.87 \\
(1.12-3.132)\end{array}$ & 0.02 & $\begin{array}{c}1.46 \\
(1.23-2.15)\end{array}$ & 0.016 \\
\hline
\end{tabular}

Abbreviations: OR, odds ratio; $\mathrm{Cl}$, confidence intervals for the OR.

a Multiple logistic regression. Models were adjusted for age, BMI, total lipids, farming activities, and place of residence.

Significant difference $(P<0.05)$

in high grades. Unlike gliomas, MGMT is unmethylated in the majority of meningiomas. No methylation of the MGMT gene was identified in meningioma grades I and II. Only one tumor had methylation in the MGMT promoter in meningioma grade III, and no methylation was observed in other stages of PBT including hemangioma and anaplastic medulloblastoma. Therefore, due to the absence of methylation in the MGMT gene promoter region within meningioma, hemangioma, and anaplastic medulloblastoma patients, it can be suggested that this methylation is specifically associated with glioma.

The results of this study also showed that the patients with BMI above 25 were more likely to have methylation in the promoter of the MGMT gene. It is evident that as BMI increases, so does body fat mass. Given the fat-solubility of OCPs, the results of this study showed that increased levels of BMI lead to rises in the amount of the pesticides in the fatty tissues, hence confirming its harmful effects on health. This finding is in line with previous studies that demonstrated an association between overweight and methylation of DNA $(14,18)$. The present study also revealed that the patients who were farmers or engaged in agricultural activities were more likely to have methylation in the MGMT gene promoter. Accordingly, Benedetti et al demonstrated that long-term exposure to pesticides induced hypermethylation of DNA in soybean farmers which may be critical for the development of adverse health effects such as cancer (19). Furthermore, due to the high methylation frequencies of the MGMT promoter in glioma patients, this study also investigated the possible associations between methylation of the MGMT promoter

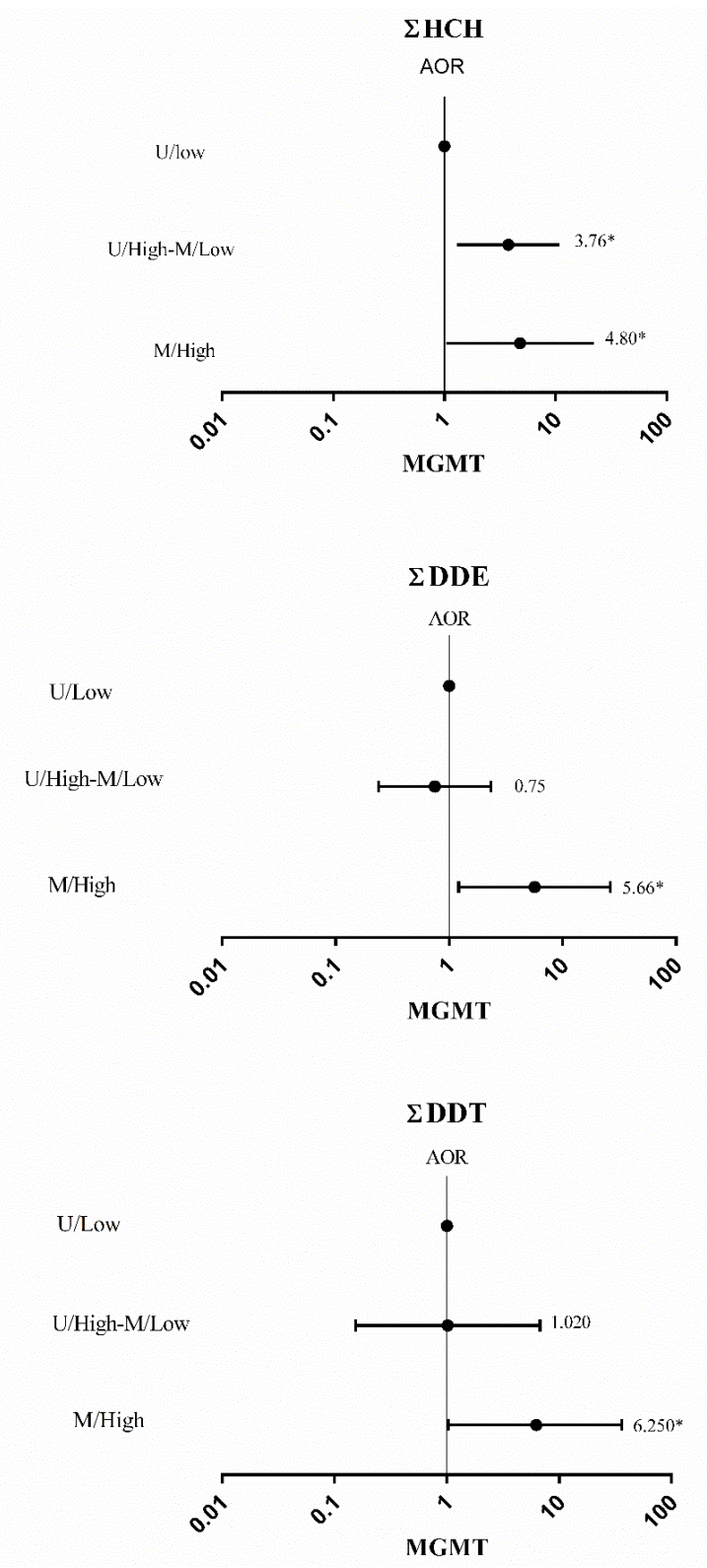

Figure 3. interactions of OCPs exposure and MGMT methylation in glioma risk. OCP exposure is categorized into high level and low level according to concentration medians. AOR (adjusted odds ratio) was adjusted for age, BMI, total lipids, farming activities, and place of residence and express the relative risk of glioma. Low risk was defined as $A O R=1$. 
and OCPs in the serum of those with gliomas. Measurement of OCPs by GC demonstrated that the levels of $\gamma-\mathrm{HCH}$, 4,4DDE, 2,4 DDT, and 4,4 DDT were significantly higher in the patients with methylated MGMT gene than in the unmethylated individuals. Logistic regression analysis also demonstrated significant associations between MGMT methylation and $\gamma-\mathrm{HCH}, 4,4 \mathrm{DDE}, 2,4 \mathrm{DDT}$, and $4,4 \mathrm{DDT}$ in the gliomas. Moreover, to examine whether the methylation status of MGMT could modify the effects of OCPs exposure in gliomas, the patients were divided into low or high exposure categories based on the median OCPs concentrations of the patients' serum, and then logistic regression was applied to investigate the possible interactions between MGMT methylation and OCPs exposure. To the best of our knowledge, this is the first study showing that the exposure to high levels of OCPs exposure statistically interacted with MGMT methylation and was associated with an elevated risk of glioma. In other words, the exposure to high levels of OCPs was associated with elevated glioma risk, particularly among the individuals with methylated MGMT promoter region. Therefore, the present study supports the hypothesis that OCPs exposure might lead to epigenetic modifications such as promoter methylation of the MGMT promoter gene. By the same token, Sabarwal and colleagues' study showed OCPs lead to DNA methylation in humans (20). In agreement with the findings of the present study, Tian et al indicated a significant association between OCPs exposure and methylation of tumor suppressor genes in hepatocellular carcinoma (21). In another study, it was shown that upon OCPs exposure, DNA methyltransferases were upregulated in MCF-7 cells (2). To the best of our knowledge, this is the first study to examine the association between methylation patterns of the MGMT promoter and OCPs in patients with brain cancer.

\section{Conclusion}

This study demonstrated that hypermethylation of the MGMT promoter is statistically related to the risk of gliomas. Given that the MGMT promoter is unmethylated in a majority of meningiomas, this methylation appeared to be specific to gliomas. These findings also suggest that hypermethylation of the MGMT promoter in glioma patients is associated with increased concentrations of OCPs derivatives in patients' serum, especially $\gamma-\mathrm{HCH}$, 4,4DDE, 2,4DDT, and 4,4DDT. Therefore, OCPs exposure may lead to the hypermethylation of the MGMT promoter gene in the brain, thereby inducing gliomas. However, further studies are needed to determine the exact contribution of OCPs to other related factors and tumor suppressor genes in gliomas.

\section{Acknowledgments}

The authors acknowledge the patients' participation and specimen donation in this study. This research was financially supported by Kerman University of Medical
Sciences, Kerman, Iran through Grant No: 94/413. This research was part of a Ph.D. thesis.

\section{Ethical issues}

Written informed consent was obtained from all participants before the questionnaires were completed and the blood and tissue samples were collected. The Declaration of Helsinki was observed in this study as the cornerstone document for instructing physicians and participants on standards. This study was approved by the Research Ethics Committee of Kerman University of Medical Sciences (Ethics code: IR.KMU.REC.1397.312).

\section{Competing interests}

The authors have none to declare.

\section{Authors' contributions}

GA: Conceptualization, methodology, supervision. FY: sample collection, performing experiments, writing the original draft, statistical analysis. MA: software, sample collection, statistical analysis. SK, VM, MHN: Resources, data curation, scientific and technical support.

\section{References}

1. Anand P, Kunnumakkara AB, Sundaram C, Harikumar KB, Tharakan ST, Lai OS, et al. Cancer is a preventable disease that requires major lifestyle changes. Pharm Res 2008; 25(9): 2097-116. doi: 10.1007/s11095-008-9661-9.

2. Ghosh K, Chatterjee B, Jayaprasad AG, Kanade SR. The persistent organochlorine pesticide endosulfan modulates multiple epigenetic regulators with oncogenic potential in MCF-7 cells. Sci Total Environ 2018; 624: 1612-22. doi: 10.1016/j.scitotenv.2017.10.058.

3. Abolhassani M, Asadikaram G, Paydar P, Fallah $\mathrm{H}$, Aghaee-Afshar M, Moazed V, et al. Organochlorine and organophosphorous pesticides may induce colorectal cancer; a case-control study. Ecotoxicol Environ Saf 2019; 178: 168-77. doi: 10.1016/j.ecoenv.2019.04.030.

4. Mortazavi N, Asadikaram G, Ebadzadeh MR, Kamalati A, Pakmanesh H, Dadgar R, et al. Organochlorine and organophosphorus pesticides and bladder cancer: A casecontrol study. J Cell Biochem 2019; 120(9): 14847-59. doi: 10.1002/jcb.28746.

5. Paydar P, Asadikaram G, Fallah H, Zeynali Nejad H, Akbari $\mathrm{H}$, Abolhassani M, et al. Serum levels of organochlorine pesticides and breast cancer risk in Iranian women. Arch Environ Contam Toxicol 2019; 77(4): 480-9. doi: 10.1007/ s00244-019-00648-3.

6. van der Plaat DA, de Jong K, de Vries M, van Diemen CC, Nedeljković I, Amin N, et al. Occupational exposure to pesticides is associated with differential DNA methylation. Occup Environ Med 2018; 75(6): 427-35. doi: 10.1136/ oemed-2017-104787.

7. Jones PA. Functions of DNA methylation: islands, start sites, gene bodies and beyond. Nat Rev Genet 2012; 13(7): 484-92. doi: 10.1038/nrg3230.

8. Zhang X, Wallace AD, Du P, Kibbe WA, Jafari N, Xie H, et al. DNA methylation alterations in response to pesticide exposure in vitro. Environ Mol Mutagen 2012; 53(7): 542-9. 
doi: 10.1002/em.21718.

9. Ohgaki H. Epidemiology of brain tumors. Methods Mol Biol 2009; 472: 323-42. doi: 10.1007/978-1-60327-4920_14.

10. Asiaf A, Ahmad ST, Malik AA, Aziz SA, Rasool Z, Masood A, et al. Protein expression and methylation of MGMT, a DNA repair gene and their correlation with clinicopathological parameters in invasive ductal carcinoma of the breast. Tumour Biol 2015; 36(8): 6485-96. doi: 10.1007/s13277015-3339-9.

11. Esteller M, Hamilton SR, Burger PC, Baylin SB, Herman JG. Inactivation of the DNA repair gene O6-methylguanineDNA methyltransferase by promoter hypermethylation is a common event in primary human neoplasia. Cancer Res 1999; 59(4): 793-7.

12. Hegi ME, Liu L, Herman JG, Stupp R, Wick W, Weller M, et al. Correlation of O6-methylguanine methyltransferase (MGMT) promoter methylation with clinical outcomes in glioblastoma and clinical strategies to modulate MGMT activity. J Clin Oncol 2008; 26(25): 4189-99. doi: 10.1200/ jco.2007.11.5964.

13. Kreth S, Thon N, Kreth FW. Epigenetics in human gliomas. Cancer Lett 2014; 342(2): 185-92. doi: 10.1016/j. canlet.2012.04.008.

14. Paydar P, Asadikaram G, Zeynali Nejad H, Akbari H, Abolhassani M, Moazed V, et al. Epigenetic modulation of BRCA-1 and MGMT genes, and histones $\mathrm{H} 4$ and $\mathrm{H} 3$ are associated with breast tumors. J Cell Biochem 2019; 120(8): 13726-36. doi: 10.1002/jcb.28645.

15. Tiwari SK, Manoj G, Prasanth K, Sivaram G, Sharma VK, Habeeb MA, et al. Simplified and versatile method for bisulfite-based DNA methylation analysis of small amounts of DNA. J Clin Lab Anal 2009; 23(3): 172-4. doi: 10.1002/ jcla.20314.

16. Zumbado M, Goethals M, Alvarez-León EE, Luzardo OP, Cabrera F, Serra-Majem L, et al. Inadvertent exposure to organochlorine pesticides DDT and derivatives in people from the Canary Islands (Spain). Sci Total Environ 2005; 339(1-3): 49-62. doi: 10.1016/j.scitotenv.2004.07.022.

17. Izadpanahi P, Anvari K, Fazl Ersi M. Glioblastoma and the significance of MGMT gene methylation. Rev Clin Med 2014; 1(3): 135-40. doi: 10.17463/rcm.2014.03.008.

18. Geurts YM, Dugué PA, Joo JE, Makalic E, Jung CH, Guan W, et al. Novel associations between blood DNA methylation and body mass index in middle-aged and older adults. Int J Obes (Lond) 2018; 42(4): 887-96. doi: 10.1038/ijo.2017.269.

19. Benedetti D, Lopes Alderete B, de Souza CT, Ferraz Dias J, Niekraszewicz L, Cappetta M, et al. DNA damage and epigenetic alteration in soybean farmers exposed to complex mixture of pesticides. Mutagenesis 2018; 33(1): 87-95. doi: 10.1093/mutage/gex035.

20. Sabarwal A, Kumar K, Singh RP. Hazardous effects of chemical pesticides on human health-cancer and other associated disorders. Environ Toxicol Pharmacol 2018; 63: 103-14. doi: 10.1016/j.etap.2018.08.018.

21. Tian M, Zhao B, Martin FL, Morais C, Liu L, Huang $\mathrm{Q}$, et al. Gene-environment interactions between GSTs polymorphisms and targeted epigenetic alterations in hepatocellular carcinoma following organochlorine pesticides (OCPs) exposure. Environ Int 2020; 134: 105313. doi: 10.1016/j.envint.2019.105313. 